\title{
Early Auditory Sensory Processing Deficits in Mouse Mutants with Reduced NMDA Receptor Function
}

\author{
Stephan Bickel*,', Hans-Peter Lipp' and Daniel Umbricht ${ }^{2}$ \\ 'Department of Neuroanatomy, Institute of Anatomy, University of Zurich, Zurich, Switzerland; 'Translational Medicine, Exploratory \\ Development, Novartis Pharma AG, Basel, Switzerland
}

\begin{abstract}
Cognitive deficits in schizophrenia include impairments at automatic, preattentive stages of sensory information processing. These deficits are evident in the prepulse inhibition- (PPI) and habituation of the auditory startle response paradigm, the paired tone paradigm in the EEG, and the peak recovery function of auditory evoked potentials (AEP). Administration of NMDA receptor antagonists reliably disrupts PPI and habituation of the startle, but not gating of AEPs in rodents. In the peak recovery paradigm, patients with schizophrenia and primates treated with NMDA receptor antagonists show reduced maximal response at long interstimulus intervals (ISI), but normal responses at short ISIs. Thus reduced NMDA receptor signalling may underlie alterations in these paradigms observed in schizophrenia. We tested the paradigms mentioned in mouse mutants with reduced expression of the NRI subunit of the NMDA receptor (N=15) and their wild-type littermates $(N=16)$. The NRI mutant mice showed impaired habituation and PPI of the auditory startle response, as well as impaired gating in the paired tone paradigm. Deficits between the two gating measures did not correlate, corroborating previous evidence that these paradigms measure distinct processes. In the peak recovery paradigm, the NRI mutants showed increased responses of the AEPs PI and $\mathrm{NI}$ at short ISIs but no difference between groups were observed at long ISIs. In conclusion, the NRI hypomorphic mice modelled sensory and sensorimotor gating and startle habituation deficits observed in schizophrenia, but failed to model alterations in the peak recovery function.
\end{abstract}

Neuropsychopharmacology (2008) 33, 1680- 1689; doi: 10.1038/sj.npp. I 301536; published online 22 August 2007

Keywords: schizophrenia; event-related potentials; NMDA receptor; prepulse inhibition; habituation; mice

\section{INTRODUCTION}

Patients with schizophrenia show deficits in early sensory information processing in the visual as well as the auditory modality (Butler et al, 2005; Javitt et al, 2000b). These impairments can be measured in behavioral paradigms (eg tone matching tasks, habituation, and prepulse inhibition of the startle response (PPI)), or EEG paradigms (mismatch negativity, P300, paired tone paradigm, peak recovery paradigm). Much effort in recent translational and genetic psychiatric research has concentrated on using these measurements to characterize endophenotypes of schizophrenia, that is neurobiological markers of fundamental biological processes underlying the disease. Endophenotypes are more closely linked to neurobiological underpinnings of disease processes than clinical phenotypes that are mainly based on symptoms and are, therefore, assumed

*Correspondence: Dr S Bickel, Department of Neuroanatomy, Institute of Anatomy, University of Zurich, Winterthurerstr. 190, 8057 Zurich, Switzerland, Tel: + 4l 4463553 49, Fax: + 4l 4463557 02, E-mail: stephan.bickel@anatom.unizh.ch

Received 28 December 2006; revised I4 July 2007; accepted 16 July 2007 to be more amenable to genetic and translational research approaches (Gottesman and Gould, 2003).

Among the most widely investigated putative endophenotypes of schizophrenia are PPI and the habituation of the startle response, gating of auditory evoked potentials (AEPs), and peak recovery functions of AEPs. PPI reflects sensorimotor gating and refers to the reduction of an auditory startle response to a startling stimulus when the stimulus is preceded by a weak prepulse by $30-500 \mathrm{~ms}$. Habituation describes the progressive decrease of a response to a repeatedly presented stimulus. It represents another measure of sensorimotor gating and is thought of as the simplest form of learning (Koch, 1999). In the paired tone paradigm, the first positive peak ( $\mathrm{P} 1$, occurring at $20 \mathrm{~ms}$ ) and the first negative peak (N1, at $40 \mathrm{~ms}$ ) of the AEPs to the second tone are suppressed, and the extent of this suppression (S2/S1 ratio) is thought to reflect a measure of auditory gating. Gating mechanisms are thought to represent inhibitory mechanisms that restrict processing of a flood of sensory input (Light and Braff, 1999). The peak recovery function describes the increase of amplitudes of AEPs as a function of increasing interstimulus intervals (ISI). The mechanism underlying this increase in peak amplitude is thought to be a decay of the refractoriness with increasing ISI of the brain areas involved in the generation 
of the AEPs (Budd et al, 1998). Thus the recovery function describes aspects of auditory sensory memory (Lu et al, 1992).

The advantage of the described paradigms is suitability for a direct translational research approach. Furthermore, they have been widely used in studies in humans and in rodents, in particular PPI (Geyer et al, 2001; Light and Braff, 1999). Deficits in PPI and auditory gating are found in a variety of psychiatric diseases (Braff et al, 2001). Most notably, alterations in both paradigms have repeatedly been described in patients with schizophrenia and their firstdegree relatives (Adler et al, 1982; Cadenhead et al, 2000; Siegel et al, 1984). Furthermore, patients with schizophrenia show deficits in the habituation of the auditory startle reflex (Braff et al, 2001; Meincke et al, 2004) and specific alterations in the AEP peak refractoriness paradigm (Shelley et al, 1999; Erwin et al, 1994).

Several lines of evidence indicate reduced NMDA receptor (NMDAR) signalling in schizophrenia (Moghaddam, 2003; Javitt and Zukin, 1991) and in particular in the pathophysiology of the observed startle habituation, gating, and AEP generation alterations in schizophrenia (Javitt et al, 2000a; Klamer et al, 2004; Geyer et al, 2001). To provide supporting evidence for this hypothesis we tested a mouse mutant with $90 \%$ reduced expression of the NR1 subunit of the NMDA receptor (subsequently named NR1 mutants in this paper) in these paradigms (Mohn et al, 1999). Previous studies have already shown PPI deficits in these mutants (Duncan et al, 2006; Fradley et al, 2005). The goal of our study was to test if the NR1 mutants would model deficits of schizophrenic patients in auditory gating, AEP generation, and habituation of the startle reflex.

\section{MATERIALS AND METHODS}

\section{Animals}

The study was approved by the ethics committee for animal research of the Kanton Zurich, Switzerland. The mouse mutants with $90 \%$ reduced expression of the NMDA receptor subunit 1 (NR1) were initially obtained from the University of North Carolina (Chapel Hill, NC, USA; Mohn et al, 1999). The heterozygous breeding animals were maintained in a pure C57Bl/6J- or 129S6/SvEv background. F1 hybrids were produced by pairing heterozygous mice from each background, the resulting homozygous $(-/-)$ offsprings and the wild-type littermates $(+/+)$ were used for the experiments. At the time of the testing the mice were an approximately 5-6 months old. In the gating paradigms 16 wild-type (eight females, eight males) and 15 mutant (seven females, eight males) mice were tested. A subset of the same animals was tested in the peak recovery paradigm (mutants: two females, nine males; wild types: six females, seven males).

\section{Surgery and EEG Recordings}

The surgery and recording procedure were described previously in more detail (Umbricht et al, 2005; Bickel et al, 2006). Shortly, EEG was recorded from four goldplated screws with miniature connectors that were implanted above the frontal- $(2.6 \mathrm{~mm}$ anterior $\pm \pm 1.5 \mathrm{~mm}$ lateral relative to bregma) and the auditory cortex ( $2.7 \mathrm{~mm}$ posterior $\pm 3.5 \mathrm{~mm}$ lateral). Electrodes over the cerebellum ( $6 \mathrm{~mm}$ posterior/midline) and one between the auditory leads served as reference and ground respectively.

During recording sessions wires were connected via miniature plugs to the connectors mounted on the animal's head, allowing the animal free range of movement in the recording box. Thus, the EEG was recorded in awake and freely moving animals. EEG recordings were acquired with a Neuroscan Synamp system (Neuroscan Labs, TX, USA) (bandpass filter $1-100 \mathrm{~Hz}, 50-\mathrm{Hz}$ notch filter, sampling rate $1 \mathrm{kHz}$ ).

Auditory stimuli were generated with a RP2 system, amplified with PA5 amplifiers, and delivered through two electrostatic loudspeakers (all Tucker-Davis Technologies, Alachua, FL). The speakers were mounted at an approximate height of $5 \mathrm{~cm}$ at the short sides of the recording box.

The same mice were tested twice in the PPI paradigm and once in the paired tone paradigm and peak recovery paradigm. Starting 1 week after the first PPI session and during subsequent 7 weeks the mice underwent surgery and electrophysiological recording, followed by the second PPI session.

\section{Auditory Gating Paradigm}

Two hundred pairs of auditory stimuli were presented with ISI of $500 \mathrm{~ms}$ and a random inter-pair interval of 9-12 s. The stimuli consisted of $10 \mathrm{~ms}$ spectrally rich tones, with frequencies ranging from 2 to $16 \mathrm{kHz}$ in $0.5 \mathrm{kHz}$ steps, and a rise/fall-time of $2 \mathrm{~ms}$. The tones were of an approximate intensity of $85 \mathrm{~dB}$ and the continuously delivered background white noise had an intensity of $65 \mathrm{~dB}$.

After the animals were placed in the recording box, they were allowed to acclimate for $2 \mathrm{~min}$. In the subsequent $2 \mathrm{~min}$, the mice were exposed to the background noise alone, before the paired tone paradigm started.

\section{Peak Recovery Paradigm}

Eight trains of 100 stimuli with different ISIs $(0.1,0.25,0.55$, $0.85,1.15,1.5,2,4 \mathrm{~s}$ ) were pseudo-randomly presented four times each. The stimuli consisted of similar frequencies as in the paired-click paradigm and had a stimulus duration of $50 \mathrm{~ms}$.

\section{Prepulse Inhibition and Startle Threshold Paradigms}

The auditory startle was assessed with a SM100 Hamilton Kinder startle monitor (Poway, CA, USA). The animals were put in a non-restrictive plastic box with adjustable ceiling that was placed on a piezo sensor-transducer in a sound attenuating chamber. The piezo disk recorded whole body flinches of the mice as reactions to the auditory startle tone in a time window of $250 \mathrm{~ms}$ after stimulus onset. The white noise bursts were presented through speakers mounted on the ceiling of the chamber. The system was calibrated with a Newton impulse calibrator every 2 weeks.

After the mice were placed in the startling box, each trial started with an acclimation period of $5 \mathrm{~min}$. The PPI paradigm consisted of trials with presentation of a startle stimulus $(120 \mathrm{~dB}, 40 \mathrm{~ms})$ alone or a prepulse with one out of 
five different prepulse intensities $(58,66,72,75,81 \mathrm{~dB}$, stimulus duration $20 \mathrm{~ms}$ ) and a startle stimulus that followed the prepulse with an interstimulus interval of $100 \mathrm{~ms}$. Trials were presented in blocks with each block consisting of one startle alone trial and the five different prepulse - startle stimulus trials in a fixed pseudo randomized order. A total of six blocks were presented in a session. Peak amplitude and latency were defined as maximal flinch response in a $250 \mathrm{~ms}$ time window after startle stimulus onset measured against baseline activity. Corresponding responses were averaged for each mouse and trial separately. PPI was measured as percentage change of the startle response magnitude following a startle stimulus preceded by a prepulse compared to the startle response to startle stimulus alone. The first PPI session was recorded 1 week before start of the electrode implantation. The second session was recorded at least 1 week following the surgery. This enabled us to control for effects of electrode implantation and investigate the influence of experience on sensorimotor gating. Startle habituation was investigated by averaging together startle alone trials, obtained in the PPI paradigm, in two consecutive blocks. Thus from the total of six startle alone trials, responses from startle alone trials in blocks 1 and 2, 3 and 4, and 5 and 6 were averaged.

\section{Data Processing and Analysis}

Data processing was performed with the Brainvision Analyzer software (Brainproducts $\mathrm{GmbH}$; München, Germany) and Matlab (Mathworks Natick, USA). For the analyses of the auditory gating paradigm, epochs were constructed that contained the first and second stimulus ( $500 \mathrm{~ms}$ prestimulus baseline and a $1500 \mathrm{~ms}$ poststimulus interval to stimulus one). These epochs were band-pass filtered $(1-80 \mathrm{~Hz}$, butterworth zero phase shift filter, $24 \mathrm{db}$ / oct) and baseline corrected. Epochs in which amplitudes exceeded $\pm 450 \mu \mathrm{V}$ in any of the four recording electrodes were excluded. Epochs were then further segmented in epochs of $50 \mathrm{~ms}$ pre- and $450 \mathrm{~ms}$ post-stimulus intervals for the first stimulus and the second stimulus and averaged for each mouse and stimulus type separately. Similar epochs were applied for the stimuli in the N1 recovery paradigm. The average of the two auditory channels was used for further analysis. AEP peaks were measured against the prestimulus baseline. P1 amplitude was defined as peak positivity within a $0-30 \mathrm{~ms}$ latency window; for $\mathrm{N} 1$, amplitude was defined as peak negativity within a 30$50 \mathrm{~ms}$ latency window; for P2, amplitude was defined as peak positivity within a $50-110 \mathrm{~ms}$ latency window. Auditory gating in the paired-click paradigm was measured by means of the ratio of the response to the second stimulus compared to the response to the first stimulus (S2S1-ratio).

\section{Statistical Analysis}

Repeated measures ANOVAs (rmANOVA) with Greenhouse-Geisser adjustments were used with group (mutants $v s$ wild type) as between-subject factor for all studies. Additional within-subject factors were chosen depending on the paradigm. Such factors were the stimulus condition (first- $v s$ second stimulus) in the paired-click paradigm, the
ISIs in the peak recovery paradigm, the intensity of prepulses, and blocks for the habituation analysis in the PPI paradigm. The rmANOVAs were followed by post hoc paired- or independent samples $t$-tests if indicated. All variables were tested on normalcy of their distribution using the Kolmogorov-Smirnov test. The assumption of normal distribution was violated by one variable (latency of peak N1 to stimulus 1 in the NR1 mutants). For group comparison of this variable the non-parametric MannWhitney $U$-test was used. A two-tailed $\alpha$ level of 0.05 was considered significant and adjusted with the Bonferroni correction if multiple tests were computed.

\section{RESULTS}

\section{Auditory Gating Paradigm}

The grand average waveforms and peak measurements obtained in this paradigm are shown in Figure 1. Peak amplitudes and latencies are shown in Table 1.

Amplitudes and gating. In both groups the $\mathrm{P} 1$ and N1 peak to the second stimulus were significantly smaller than the corresponding peaks to the first stimulus (stimulus effects: P1: $\quad \mathrm{F}(1,29)=225.91, \quad p<0.01 ; \quad \mathrm{N} 1: \quad \mathrm{F}(1,29)=108.05$, $p<0.01)$. Auditory gating for the P1 and the N1 peak was significantly impaired in the NR1 mutants compared to their wild-type littermates, as shown by the increased S2S1 ratios in the mutants (independent $t$-test: $\mathrm{P} 1: p<0.01, \mathrm{~N} 1$ : $p<0.01)$. The peak amplitudes to the first stimulus for the $\mathrm{P} 1$ and the N1 component were not statistically different between the groups (P1: $p=0.3, \mathrm{~N} 1: p=0.4$ ). Thus increased ratios in the NR1 mutants were due to augmented responses to the second stimulus rather than due to reduced amplitudes to the first stimulus (P1: $p<0.01, \mathrm{~N} 1: p<0.01)$.

Latencies. A rmANOVA with stimulus condition as repeated measures computed for each peak separately showed that the mean latencies of the peaks P1 and N1 were significantly longer in the NR1 mutants (effect of genotype: $\mathrm{P} 1: \mathrm{F}(1,29)=20.25, p<0.01 ; \mathrm{N} 1: \mathrm{F}(1,29)=22.78$, $p<0.01)$. The latency was prolonged in response to both, the first and the second tone (P1 to tone $1 /$ tone $2: p=0.01 /$ $p<0.01 ; \mathrm{N} 1: p<0.01 /$ Mann-Whitney $U$-test $p<0.01)$.

\section{Peak Recovery Paradigm}

Grand averages and peak measurements are displayed in Figures 2, 3 and the Supplementary Figure 2. Peak amplitudes and latencies are shown in Table 1.

\section{P1}

Amplitudes. The mean peak amplitude showed an ISI effect across both groups $(\mathrm{F}(2.2,47.8)=76.88, p<0.01)$ and a ISI $\times$ genotype interaction $(\mathrm{F}(2.2,47.8)=3.51, p=0.03)$ (Figure 2). This interaction was due to a greater increase of the P1 amplitude at short ISIs (Figure 3). To test this we computed the sequential increases of the amplitudes from short to long ISIs. A rmANOVA of these incremental increases demonstrated a significant ISI $\times$ genotype interaction $(\mathrm{F}(3.4,74.7)=3.79, p=0.01)$. A significant difference 


\section{Paired Tone Paradigm}
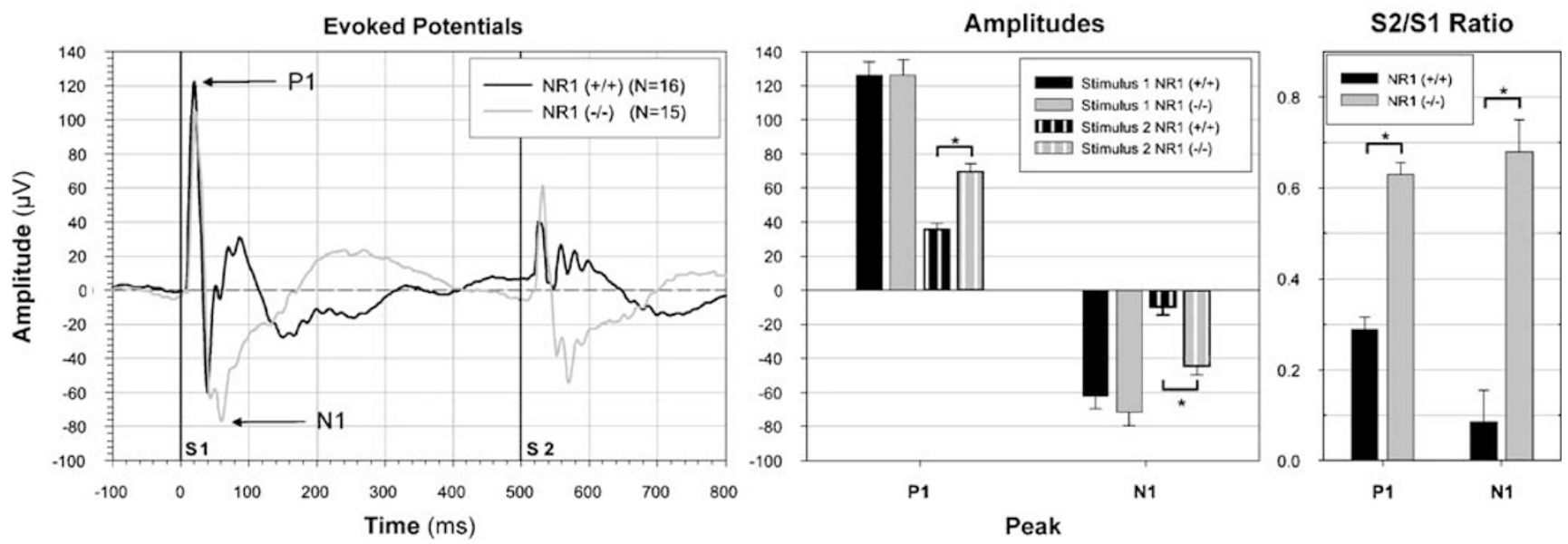

Figure I The grand averages of the auditory evoked potentials (left graph) show that both groups show a reduction of the peaks $\mathrm{PI}$ and $\mathrm{NI}$ in the response to the second tone compared to the first. However, the suppression is more pronounced in the control group as compared to the NRI hypomorphic mice (middle graph). The graph on the right shows peak amplitude ratios (response to tone 2/response to tone I). Also note the prolonged $\mathrm{NI}$ component in the mutant group (left graph) (asterisks indicate $p<0.01$, error bars show SEM).

in the amplitude increase was found from ISI 0.25 to $0.55 \mathrm{~s}$ $(t=-5.2, \mathrm{df}=22, p<0.01)$.

Latencies. The NR1 hypomorphic mice showed significantly longer peak latencies across all ISIs (mutants: $20.7 \pm 0.32 \mathrm{~ms}$, wild types: $19 \pm 0.29 \mathrm{~ms}$, effect of genotype $\mathrm{F}(1,22)=16.03, p<0.01)$. We also observed an effect of ISI $(\mathrm{F}(2.7,58.7)=30.05, p<0.01)$ and a ISI $\times$ genotype interaction $(\mathrm{F}(2.7,58.7)=2.86, \quad p=0.05)$. This was due to increasing latencies with lengthening of the ISI; this increase was greater in the mutant group.

\section{N1}

Amplitudes. Mean N1 peak amplitudes increased in both groups as a function of ISI $(\mathrm{F}(3.2,69.7)=60.7, p<0.01)$ (Figures 2 and 3 ). In addition, an ISI $\times$ genotype interaction was observed $(\mathrm{F}(3.2,69.7)=53.1, p<0.01)$ again due to a greater increase of amplitudes at short ISIs in the NR1 mutants $(F(4.1,90.1)=3.9, p<0.01)$. The groups significantly differed the incremental amplitude increase from ISI 0.1 to $0.25 \mathrm{~s}(t=4.6, \mathrm{df}=22, p<0.01)$.

Latencies. Similar to the P1 peak, mean peak latencies of the $\mathrm{N} 1$ were delayed across all ISIs in the NR1 mutant mice (mutants: $42.1 \pm 0.62 \mathrm{~ms}$, wild types: $38.5 \pm 0.68 \mathrm{~ms}$, effect of group $\mathrm{F}(1,22)=14.88, p<0.01)$. There was also an effect of ISI $(\mathrm{F}(3,64.2)=4.67, p<0.01)$ but no significant ISI $\times$ genotype interaction $(\mathrm{F}(3,64.2)=2.4, p=0.08)$.

\section{P2}

Amplitudes. A striking difference in the morphology of the waveforms is apparent between groups in the time window following the N1 component in both EEG paradigms (Figures 1 and 2). While wild type mice generated an ISIdependent $\mathrm{P} 2$ component following $\mathrm{N} 1$, this component was not observed in the NR1 mutant mice (ISI $\times$ genotype
$\mathrm{F}(4,87.3)=11.7, p<0.01)$ (Figure 2). P2 peak amplitudes in the control group increased with longer ISIs $(\mathrm{F}(2.8,33.6)=$ $11.1, p<0.01)$. In the NR1 mutants an ongoing negative component that showed a similar recovery pattern with increasing ISI as the peak N1 was observed during the P2 time window, reflected by a missing ISI $\times$ peak interaction for $\mathrm{N} 1$ and the negative peak measured in the P2 time window in the mutant group $(\mathrm{F}(2.7,26.6)=1.2, p=0.34)$. We did not observe an ISI-dependent decrease of the negative gradient during this component. This would have indicated that $\mathrm{P} 2$ was generated, but masked by the ongoing N1 component.

Latencies. In the wild-type mice, the mean P2 peak latency was $74.6 \pm 3.4 \mathrm{~ms}$ and there was no effect of ISI on peak latency $(\mathrm{F}(3.9,46.9)=1.8, p=0.16)$.

\section{Prepulse Inhibition and Habituation of the Auditory Startle}

All mice were tested twice in the PPI paradigm, once before and once after electrode implantation.

The startle magnitude in the startle alone trials did not show a session, or session $\times$ genotype effect. Furthermore, for the habituation analysis with blocks and sessions as repeated measures there was no effect of session or session $\times$ genotype interaction (for results see Supplementary Figure S1). Thus, to increase statistical power for the habituation analysis, we averaged the data of the two sessions for the startle response for each mouse. A significant effect of genotype indicated increased startle magnitudes in the NR1 mutants $(\mathrm{F}(1,29)=8.83, p<0.01)$. While the control group showed a habituation of the startle response, the mutant group showed no change of response amplitude during the sessions, as indicated by a significant block $\times$ genotype interaction $(\mathrm{F}(1.6,46.2)=3.74, p=0.04)$ (Figure 4). While in the control group responses were significantly decreased in the third compared to the first 
Table I Peak Amplitudes and Latencies with SEM of the Auditory Evoked Potentials

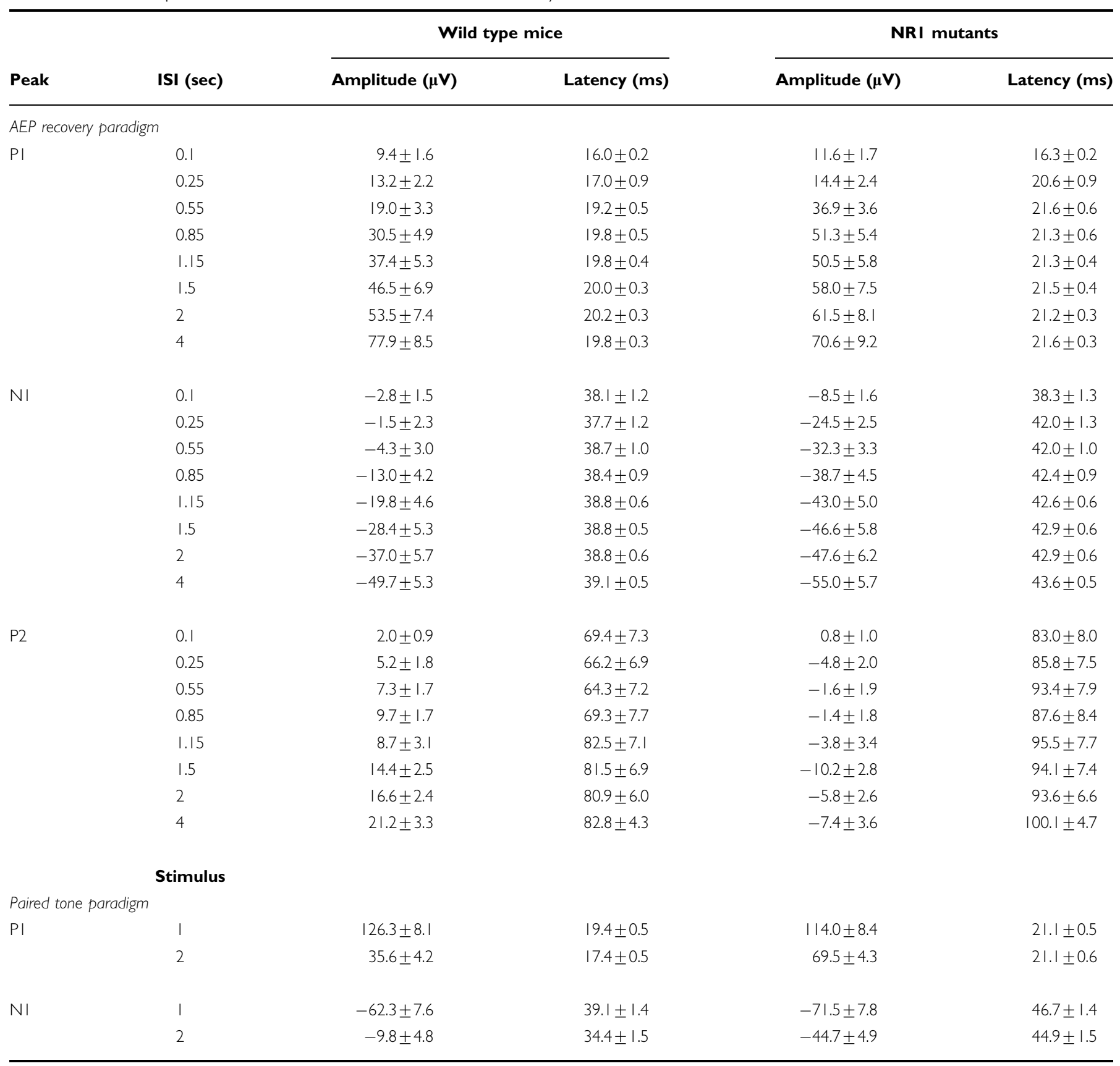

block $(t=5.5, \mathrm{df}=15, p<0.01)$ there was no difference in the mutant group between blocks $(t=0.85, \mathrm{df}=14$, $p=0.41)$.

There was no significant difference in PPI between the two sessions (effect of session $\mathrm{F}(1,29)=3.6, p=0.07$ ) and no significant session $\times$ genotype interaction $(F(1,29)=3.6$, $p=0.88$ ) (Figure 5). Thus, further PPI analysis used collapsed data across the two sessions. In line with results from previous studies (Duncan et al, 2006; Fradley et al, 2005) PPI was significantly reduced in the mutants (effect of genotype $\mathrm{F}(1,29)=5.8, p=0.02)$. We also observed a significant intensity $\times$ genotype interaction $(\mathrm{F}(2.7,78.3)=$ 3.7, $p=0.02)$. Significant rmANOVAs for each group separately suggested that prepulse-dependent PPI was apparent in both groups (wild types: $F(2,29.4)=19.7$, $p<0.01$, NR1 mutants: $\mathrm{F}(2.9,40.6)=24.1, p<0.01)$. The significant genotype $\times$ intensity interaction was due to more pronounced prepulse dependent PPI in the mutant group compared to the wild types, in other words PPI increased more in the mutant group with increasing intensity of the prepulse (Figure 5).

There was no significant correlation of PPI, averaged across all prepulse intensities, and the S2S1 ratio of the paired-click paradigm in both groups for the peak N1 and the peak P1 in the wild type group. The NR1 mutant group showed a significant correlation between the PPI and the P1 ratio (Pearson correlation coefficient $-0.576, p=0.024$ ). However, this significant result was mainly driven by two 


\section{AEP Peak Recovery Paradigm}
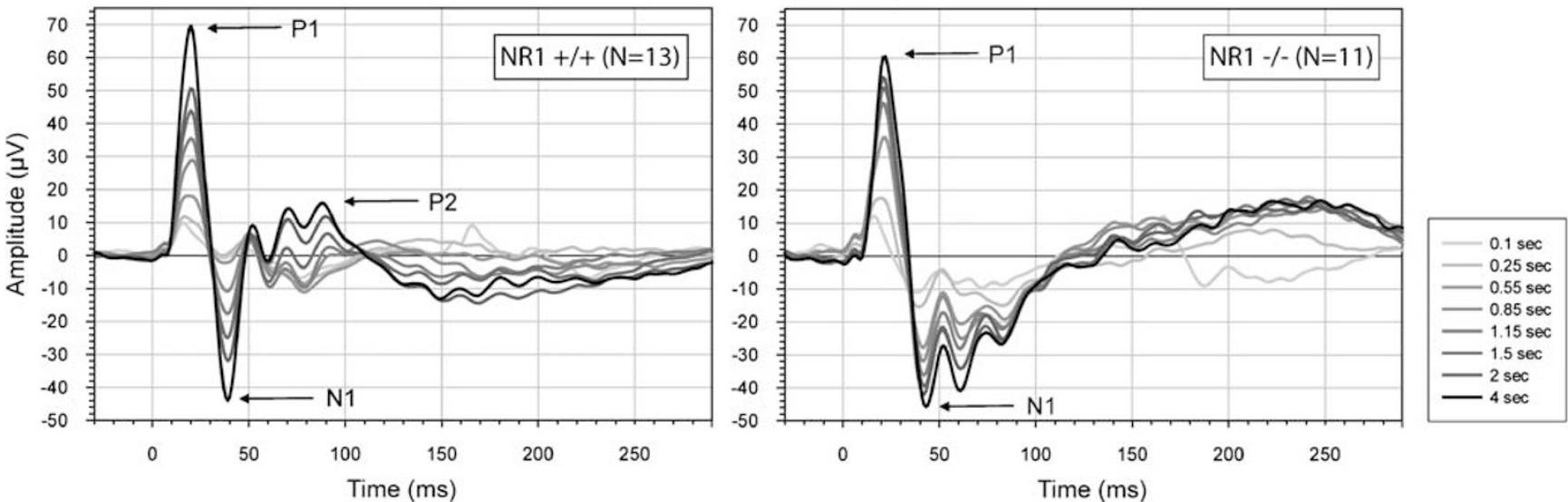

Figure 2 Grand averages of the AEP with different ISI. The amplitudes of AEP increase with ISIs in both groups. While in the wild type group (left) an ISIdependent positive component develops following the NI component, this component is missing in the NRI hypomorphic mice (right).

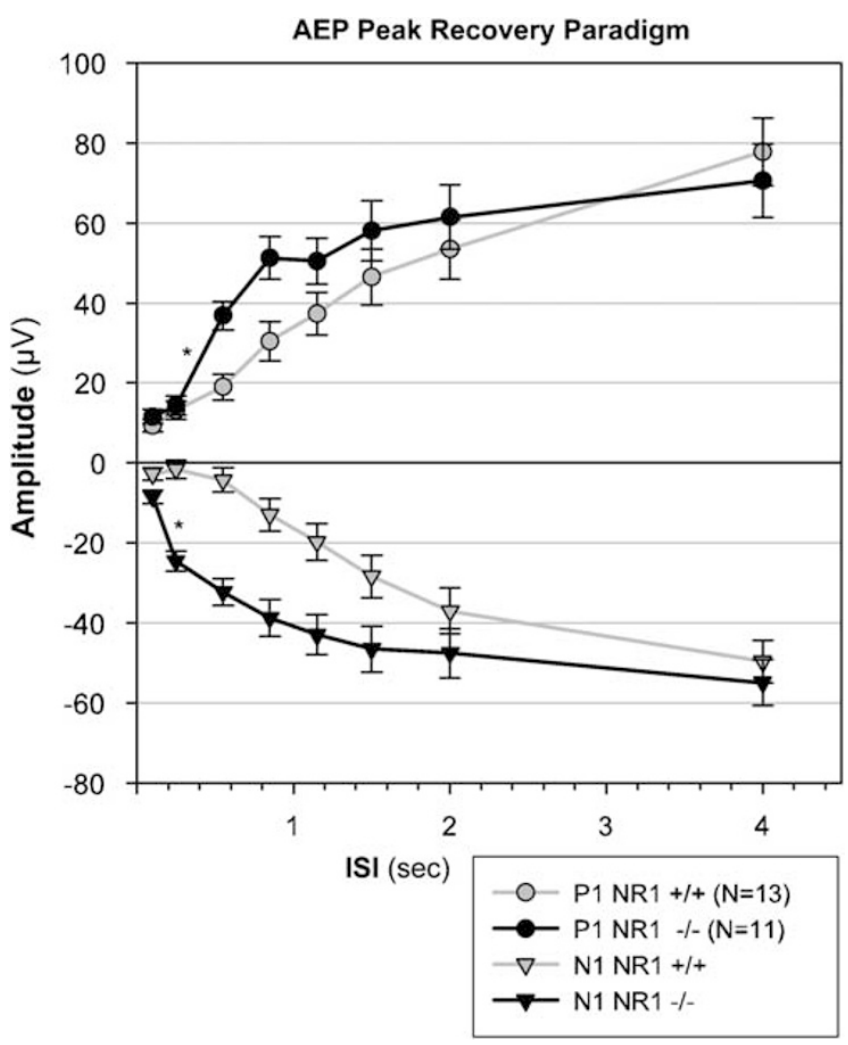

Figure 3 The NRI mutants show larger responses at short ISI compared to the control group. However, there are no differences in the maximal responses (asterisks indicate $p<0.01$; error bars show SEM).

outliers and removal of those abolished the significant result $(-0.171, p=0.576)$. Thus, these results suggest a lack of correlation between PPI and gating of peaks P1 and N1.

\section{DISCUSSION}

The present results show that mouse mutants with reduced expression of the NMDAR subunit 1 model deficits of schizophrenic patients in habituation and PPI of the

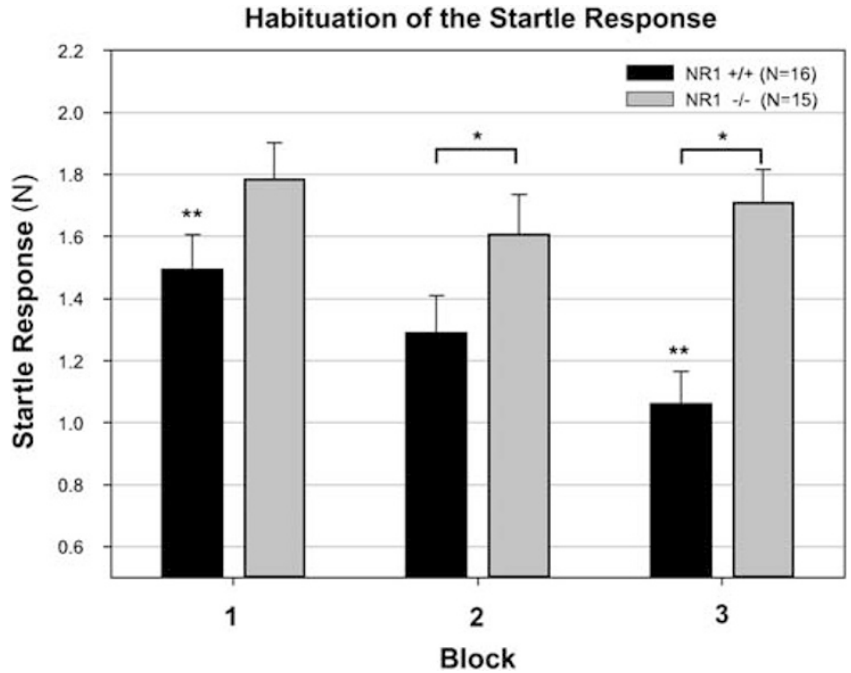

Figure 4 During the sessions the wild type mice developed habituation of the startle response. However, no habituation was observed in the NRI mutant mice. (asterisks indicate $p<0.01$; error bars show SEM).

auditory startle and in auditory gating in the paired tone paradigm. However, they differ in the pattern of AEP peak refractoriness.

\section{Auditory Gating}

Auditory gating was significantly disrupted for both investigated peaks ( $\mathrm{P} 1, \mathrm{~N} 1)$ in the NR1 mutant mice as compared to their wild-type littermates. Decreased gating in the paired tone paradigm, that is an increased S2S1-peak ratio, can either result from a lack of suppression of the response to the second tone or a decreased response to the first tone compared to the control group. In patients with schizophrenia impaired gating is more commonly observed due to a decreased response to the first tone. However, evidence for both types of disruption can be found (Hong et al, 2004; Ward et al, 1996; Freedman et al, 1983). In our study decreased gating of both peaks P1 and N1 in the NR1 


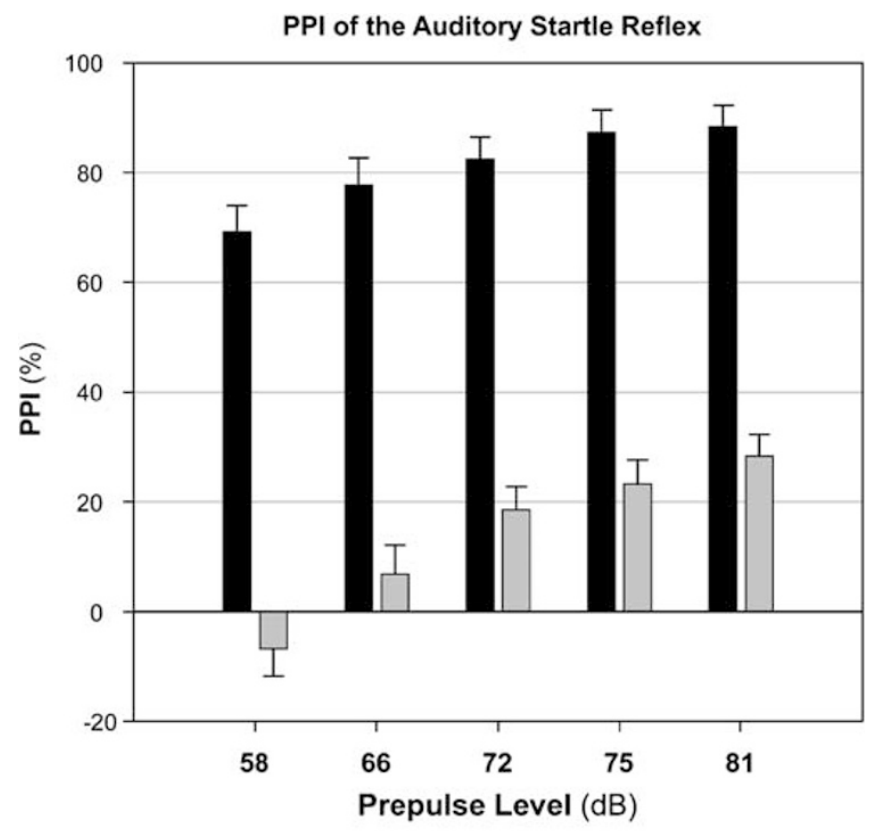

$\mathrm{NR} 1+/+(\mathrm{N}=16)$ $\mathrm{NR} 1 \% \quad(\mathrm{~N}=15)$

Figure $5 \mathrm{PPI}$ in the NRI mutants was decreased compared to control group at every prepulse intensity level (error bars show SEM).

mutant mice was caused by reduced suppression of the response to the second tone (Figure 1).

Based on previous studies, we reason that the mouse correlates of the P50 and N100 are the P20 and N40 respectively (named $\mathrm{P} 1$ and $\mathrm{N} 1$ in this paper) (Umbricht et al, 2004b; Connolly et al, 2004; Siegel et al, 2003). Most gating studies in humans have focused on the P50 component of the human auditory AEP and only few on the N100. However, gating has been shown for both peaks. In schizophrenia gating of both peaks is disrupted (Boutros et al, 1999; Rosburg et al, 2004). Thus the NR1 mutant mice show gating deficits comparable to those observed in schizophrenia.

In contrast to the reliable disruption of PPI in rodents by NMDAR antagonists, it is still controversial if reduced NMDAR signalling affects auditory gating in the paired tone paradigm. So far, most, but not all, studies in rats showed impairments of $\mathrm{N} 40$-gating (the putative rat correlate of the human N100) with NMDAR blocking (Miller et al, 1992; de Bruin et al, 1999; Swerdlow et al, 2006). However, no effect of NMDAR antagonists on auditory gating was observed in a study in mice (Connolly et al, 2004). Furthermore, two studies in healthy human subjects showed no effect of ketamine on auditory gating (Oranje et al, 2002; van Berckel et al, 1998). The prominent auditory gating deficit in the NR1 mutants contrasts with the unaltered gating in several studies using acute pharmacological NMDAR blockade and possibly indicates that chronic deficient NMDAR-mediated signalling, perhaps even through development, has to be present to cause the auditory gating deficits. Hypothetically, alterations in hippocampal inhibitory interneurons may underlie the observed deficits in the NR1 mutants. CA3 interneurons have been suggested to be the crucial final neurons mediating hippocampal sensory gating (Turetsky et al, 2006). Repeated but not single application of NMDAR antagonists decreased the number of interneurons expressing parvalbumin $\left(\mathrm{a} \mathrm{Ca}^{2+}\right.$-binding protein expressed by a subclass of interneurons) in the hippocampus of rodents (Keilhoff et al, 2004; Cunningham et al, 2006). Interestingly, alterations in hippocampal interneurons have been suggested to be involved in the pathophysiology of schizophrenia, and a specific reduction of parvalbumin expressing interneurons has been observed in the hippocampus of patients with schizophrenia (Heckers and Konradi, 2002; Zhang and Reynolds, 2002). However, further studies investigating interneurons in the NR1 mutants are needed to test this hypothesis.

The lack of a correlation between PPI and auditory gating in the paired tone paradigm further corroborates evidence from human and animal studies that these paradigms measure two distinct mechanisms (Brenner et al, 2004; Ellenbroek et al, 1999; Swerdlow et al, 2006).

\section{Aep Peak Refractoriness}

The NR1 mutants showed steeper rise of the P1 and N1 peak amplitudes with increasing ISI compared to the control group, suggestive of a faster decay of the auditory sensory memory trace (Lu et al, 1992). However, the maximal response did not differ between the groups (Figures 2 and 3 ). Thus our findings differ from the peak recovery profile observed in patients with schizophrenia who show a deficit in generation of the maximum P1 and $\mathrm{N} 1$ at long ISIs, but no difference in the slope of the peak recovery function (Roth et al, 1980; Shelley et al, 1999). Our initial hypothesis to find a similar profile in the NR1 mutant mice was based on studies in rats, non-human primates and healthy volunteers, in which such a profile was reproduced by acute application of NMDAR antagonists, pointing to a possible involvement of the NMDAR in this deficit (Javitt et al, 2000a; Ehlers et al, 1992; Umbricht et al, 2004a). Furthermore, previous studies have shown that the mouse AEP peaks P1, N1, and P2 display refractory curves comparable to their putative human correlates ( $\mathrm{P} 1, \mathrm{~N} 1$, P2) (Umbricht et al, 2004b; Maxwell et al, 2004). Also, in two mouse studies that investigated the effects of pharmacological NMDAR blockade P1 was increased and N1 changed dependent on mouse strain (Maxwell et al, 2006; Connolly et al, 2004). However, since only one long ISI (9 s) was used in these studies, the effect of NMDAR antagonism on responses to tones with short ISIs in mice is unknown. Taken together, most studies indicate that reduced NMDAR-mediated signalling reduces $\mathrm{P} 1$ and $\mathrm{N} 1$ in different species preferentially at long ISIs but the available evidence is currently not conclusive.

The most parsimonious explanations for the observed results in our study is that deficient NMDAR signalling throughout development, as present in the constitutive NR1 mutants, causes alterations in the underlying neural circuitry that differs from abnormalities induced by acute blockade by NMDAR antagonists and those present in schizophrenia. Other possible explanations are that (1) deficient NMDAR-mediated signalling is not the main abnormality causing alterations of the peak recovery in 
schizophrenia, and (2) the $\mathrm{P} 1$ and $\mathrm{N} 1$ peaks in mice do not represent the associate human peaks although the available evidence speaks against that (Umbricht et al, 2004b; Maxwell et al, 2004).

\section{Alterations in AEP Morphology}

While the initial registration of the stimuli as represented in the first $50 \mathrm{~ms}$ in the AEPs showed similar morphology of the waveforms in the two groups, striking differences were apparent in the NR1 mutant mice in the time window following the $\mathrm{N} 1$ peak. In line with previous studies, the control group showed an ISI-dependent generation of a P2 component following N1 (Figure 2) (Umbricht et al, 2004b). However, in the NR1 mutants this P2 component was lacking or masked by an ongoing negative activity after the N1 component. Furthermore, the negative slow wave in the time window from 100 to $300 \mathrm{~ms}$ showed inverse polarity in the NR1 mutant mice (Figures 1 and 2). Thus, besides the described alterations in the early auditory information processing in the NR1 mutants, also later hierarchical stages of information processing seem to be affected by the mutation of the NMDAR. However, these findings are difficult to interpret with the current available data since no such alterations are observed in either pharmacological animal models of reduced NMDAR signalling or in patients with schizophrenia. They may indicate far-reaching consequences of reduced NMDAR signalling throughout the whole developmental period as compared to short-lasting pharmacological blockade of the NMDAR in adulthood. Single unit and AEP studies in rats suggested that the slow wave N2 and $\mathrm{P} 2$ represent an inhibitory process suppressing the early excitation reflected by the $\mathrm{P} 1 / \mathrm{N} 1$ deflection observed in the cortical AEP of the rat (Metherate 1998; Sukov and Barth 1998). Thus the prolonged N1 component in the NR1 mutant mice may indicate a disruption of this inhibitory process. However as mentioned by Metherate, single unit responses and AEPs only overlap in the first $20 \mathrm{~ms}$ poststimulus, thus one has to be cautious when comparing findings from these two approaches (Metherate 1998). It also has to be mentioned that these alterations were not observed in earlier recordings in these mouse mutants in which a different reference electrode (above frontal cortex) than in the present study (above the cerebellum) was used. This highlights the importance of the recording setup when interpreting data and comparing different studies.

\section{Habituation and PPI of the Startle}

The very robust PPI deficits in the NR1 mutants reproduces findings from several previous studies (Duncan et al, 2006; Fradley et al, 2005) and agree with pharmacological studies that showed a reliable disruption of PPI in rodents and monkeys by NMDAR antagonists (Linn et al, 2003; Geyer et al, 2001). However, it has to be taken into account that these results contrast with most human studies, in which NMDAR antagonists either had no influence or even increased PPI (Braff et al, 2001; van Berckel et al, 1998; Abel et al, 2003).

Furthermore, we found group differences in the prepulse intensity dependence of the PPI. The NR1 mutants showed a bigger increase in PPI with increasing prepulse intensity compared to the wild type group. This contrasts to findings in schizophrenia, where prepulse-dependent PPI is usually unaltered (Braff et al, 1999; Grillon et al, 1992). One possible explanation for the finding in our study is a putative ceiling effect of PPI in the control group, since this group already reached relatively high PPI values in trials with the lowest prepulse intensities.

A new finding in our study is the observation of impaired habituation of the startle response in these mutants. This parallels findings in schizophrenia and pharmacological rodent models of reduced NMDAR-mediated signalling (Ludewig et al, 2003; Klamer et al, 2004). Habituation reflects a simple form of non-associative learning and its generation has been located in the afferent sensory pathway of the neural startle circuit (Pilz et al, 2004). It has been suggested that habituation to initially novel stimuli may be essential for processes such as orienting responses and selective attention (Geyer et al, 1990).

In conclusion, the present study suggests involvement of reduced NMDAR-mediated signalling in the pathophysiology of deficits in habituation and PPI of the auditory startle reflex and auditory gating in the paired tone paradigm in schizophrenia. However, the reduced P1 and N1 amplitudes at long ISI in patients with schizophrenia could not be modelled with this mouse model of NMDAR hypofunction. Thus, our results provide further supporting evidence for the hypothesis that deficient NMDAR functioning plays an important role in the pathophysiology of abnormal information processing in schizophrenia.

\section{ACKNOWLEDGEMENTS}

We thank Professor Beverly Koller, Department of Genetics, UNC Chapel Hill, USA, for providing the NMDA receptor mutants.

\section{DISCLOSURE/CONFLICT OF INTEREST}

None of the authors have to disclose a potential conflict of interest that might bias the presented work in this manuscript. This work was supported by grants from the Swiss National Science Foundation, the National Alliance for Research on Schizophrenia and Depression (NARSAD) to Dr Umbricht and from the 'National Competence Center for Research (NCCR) 'Neural Plasticity and Repair' to Dr Lipp and Dr Fritschy. Dr Umbricht is employed by Novartis, Pharma AG, Switzerland.

\section{REFERENCES}

Abel KM, Allin MP, Hemsley DR, Geyer MA (2003). Low dose ketamine increases prepulse inhibition in healthy men. Neuropharmacology 44: 729-737.

Adler LE, Pachtman E, Franks RD, Pecevich M, Waldo MC, Freedman R (1982). Neurophysiological evidence for a defect in neuronal mechanisms involved in sensory gating in schizophrenia. Biol Psychiatry 17: 639-654.

Bickel S, Lipp HP, Umbricht D (2006). Impaired attentional modulation of auditory evoked potentials in N-methyl-daspartate NR1 hypomorphic mice. Genes Brain Behav. Print copy in press (originally published online November 17, 2006, at 
www.blackwell-synergy.com/doi/abs/10.1111/j.1601-

183X.2006.00283.x).

Boutros NN, Belger A, Campbell D, D’Souza C, Krystal J (1999). Comparison of four components of sensory gating in schizophrenia and normal subjects: a preliminary report. Psychiatry Res 88: 119-130.

Braff DL, Geyer MA, Swerdlow NR (2001). Human studies of prepulse inhibition of startle: normal subjects, patient groups, and pharmacological studies. Psychopharmacology (Berl) 156: 234-258.

Braff DL, Swerdlow NR, Geyer MA (1999). Symptom correlates of prepulse inhibition deficits in male schizophrenic patients. Am J Psychiatry 156: 596-602.

Brenner CA, Edwards CR, Carroll CA, Kieffaber PD, Hetrick WP (2004). P50 and acoustic startle gating are not related in healthy participants. Psychophysiology 41: 702-708.

Budd TW, Barry RJ, Gordon E, Rennie C, Michie PT (1998). Decrement of the $\mathrm{N} 1$ auditory event-related potential with stimulus repetition: habituation vs refractoriness. Int J Psychophysiol 31: 51-68.

Butler PD, Zemon V, Schechter I, Saperstein AM, Hoptman MJ, Lim KO et al (2005). Early-stage visual processing and cortical amplification deficits in schizophrenia. Arch Gen Psychiatry 62: 495-504.

Cadenhead KS, Swerdlow NR, Shafer KM, Diaz M, Braff DL (2000). Modulation of the startle response and startle laterality in relatives of schizophrenic patients and in subjects with schizotypal personality disorder: evidence of inhibitory deficits. Am J Psychiatry 157: 1660-1668.

Connolly PM, Maxwell C, Liang Y, Kahn JB, Kanes SJ, Abel T et al (2004). The effects of ketamine vary among inbred mouse strains and mimic schizophrenia for the P80, but not P20 or N40 auditory ERP components. Neurochem Res 29: 1179-1188.

Cunningham MO, Hunt J, Middleton S, LeBeau FE, Gillies MJ, Davies CH et al (2006). Region-specific reduction in entorhinal gamma oscillations and parvalbumin-immunoreactive neurons in animal models of psychiatric illness. J Neurosci 26: 2767-2776.

de Bruin NM, Ellenbroek BA, Cools AR, Coenen AM, van Luijtelaar EL (1999). Differential effects of ketamine on gating of auditory evoked potentials and prepulse inhibition in rats. Psychopharmacology (Berl) 142: 9-17.

Duncan GE, Moy SS, Lieberman JA, Koller BH (2006). Effects of haloperidol, clozapine, and quetiapine on sensorimotor gating in a genetic model of reduced NMDA receptor function. Psychopharmacology (Berl) 184: 190-200.

Ehlers CL, Kaneko WM, Wall TL, Chaplin RI (1992). Effects of dizocilpine (MK-801) and ethanol on the EEG and event-related potentials (ERPS) in rats. Neuropharmacology 31: 369-378.

Ellenbroek BA, van LG, Frenken M, Cools AR (1999). Sensory gating in rats: lack of correlation between auditory evoked potential gating and prepulse inhibition. Schizophr Bull 25: 777-788.

Erwin RJ, Shtasel D, Gur RE (1994). Effects of medication history on midlatency auditory evoked responses in schizophrenia. Schizophr Res 11: 251-258.

Fradley RL, O'Meara GF, Newman RJ, Andrieux A, Job D, Reynolds DS (2005). STOP knockout and NMDA NR1 hypomorphic mice exhibit deficits in sensorimotor gating. Behav Brain Res 163: 257-264.

Freedman R, Adler LE, Waldo MC, Pachtman E, Franks RD (1983). Neurophysiological evidence for a defect in inhibitory pathways in schizophrenia: comparison of medicated and drug-free patients. Biol Psychiatry 18: 537-551.

Geyer MA, Krebs-Thomson K, Braff DL, Swerdlow NR (2001). Pharmacological studies of prepulse inhibition models of sensorimotor gating deficits in schizophrenia: a decade in review. Psychopharmacology (Berl) 156: 117-154.
Geyer MA, Swerdlow NR, Mansbach RS, Braff DL (1990). Startle response models of sensorimotor gating and habituation deficits in schizophrenia. Brain Res Bull 25: 485-498.

Gottesman II, Gould TD (2003). The endophenotype concept in psychiatry: etymology and strategic intentions. Am J Psychiatry 160: $636-645$.

Grillon C, Ameli R, Charney DS, Krystal J, Braff D (1992). Startle gating deficits occur across prepulse intensities in schizophrenic patients. Biol Psychiatry 32: 939-943.

Heckers S, Konradi C (2002). Hippocampal neurons in schizophrenia. J Neural Transm 109: 891-905.

Hong LE, Summerfelt A, McMahon RP, Thaker GK, Buchanan RW (2004). Gamma/beta oscillation and sensory gating deficit in schizophrenia. Neuroreport 15: 155-159.

Javitt DC, Jayachandra M, Lindsley RW, Specht CM, Schroeder CE (2000a). Schizophrenia-like deficits in auditory P1 and N1 refractoriness induced by the psychomimetic agent phencyclidine (PCP). Clin Neurophysiol 111: 833-836.

Javitt DC, Shelley AM, Silipo G, Lieberman JA (2000b). Deficits in auditory and visual context-dependent processing in schizophrenia: defining the pattern. Arch Gen Psychiatry 57: 1131-1137.

Javitt DC, Zukin SR (1991). Recent advances in the phencyclidine model of schizophrenia. Am J Psychiatry 148: 1301-1308.

Keilhoff G, Becker A, Grecksch G, Wolf G, Bernstein HG (2004). Repeated application of ketamine to rats induces changes in the hippocampal expression of parvalbumin, neuronal nitric oxide synthase and cFOS similar to those found in human schizophrenia. Neuroscience 126: 591-598.

Klamer D, Palsson E, Revesz A, Engel JA, Svensson L (2004). Habituation of acoustic startle is disrupted by psychotomimetic drugs: differential dependence on dopaminergic and nitric oxide modulatory mechanisms. Psychopharmacology (Berl) 176: $440-450$.

Koch M (1999). The neurobiology of startle. Prog Neurobiol 59: 107-128.

Light GA, Braff DL (1999). Human and animal studies of schizophrenia-related gating deficits. Curr Psychiatry Rep 1: 31-40.

Linn GS, Negi SS, Gerum SV, Javitt DC (2003). Reversal of phencyclidine-induced prepulse inhibition deficits by clozapine in monkeys. Psychopharmacology (Berl) 169: 234-239.

Lu ZL, Williamson SJ, Kaufman L (1992). Behavioral lifetime of human auditory sensory memory predicted by physiological measures. Science 258: 1668-1670.

Ludewig K, Geyer MA, Vollenweider FX (2003). Deficits in prepulse inhibition and habituation in never-medicated, firstepisode schizophrenia. Biol Psychiatry 54: 121-128.

Maxwell CR, Ehrlichman RS, Liang Y, Trief D, Kanes SJ, Karp J et al (2006). Ketamine produces lasting disruptions in encoding of sensory stimuli. J Pharmacol Exp Ther 316: 315-324.

Maxwell CR, Liang Y, Weightman BD, Kanes SJ, Abel T, Gur RE et al (2004). Effects of chronic olanzapine and haloperidol differ on the mouse N1 auditory evoked potential. Neuropsychopharmacology 29: 739-746.

Meincke U, Light GA, Geyer MA, Braff DL, Gouzoulis-Mayfrank E (2004). Sensitization and habituation of the acoustic startle reflex in patients with schizophrenia. Psychiatry Res 126: 51-61.

Metherate R (1998). Synaptic mechanisms in auditory cortex function. Front Biosci 3: d494-d501.

Miller CL, Bickford PC, Luntz-Leybman V, Adler LE, Gerhardt GA, Freedman R (1992). Phencyclidine and auditory sensory gating in the hippocampus of the rat. Neuropharmacology 31: 1041-1048

Moghaddam B (2003). Bringing order to the glutamate chaos in schizophrenia. Neuron 40: 881-884.

Mohn AR, Gainetdinov RR, Caron MG, Koller BH (1999). Mice with reduced NMDA receptor expression display behaviors related to schizophrenia. Cell 98: 427-436. 
Oranje B, Gispen-de Wied CC, Verbaten MN, Kahn RS (2002). Modulating sensory gating in healthy volunteers: the effects of ketamine and haloperidol. Biol Psychiatry 52: 887-895.

Pilz PK, Carl TD, Plappert CF (2004). Habituation of the acoustic and the tactile startle responses in mice: two independent sensory processes. Behav Neurosci 118: 975-983.

Rosburg T, Trautner P, Korzyukov OA, Boutros NN, Schaller C, Elger CE et al (2004). Short-term habituation of the intracranially recorded auditory evoked potentials P50 and N100. Neurosci Lett 372: 245-249.

Roth WT, Horvath TB, Pfefferbaum A, Kopell BS (1980). Eventrelated potentials in schizophrenics. Electroencephalogr Clin Neurophysiol 48: 127-139.

Shelley AM, Silipo G, Javitt DC (1999). Diminished responsiveness of ERPs in schizophrenic subjects to changes in auditory stimulation parameters: implications for theories of cortical dysfunction. Schizophr Res 37: 65-79.

Siegel C, Waldo M, Mizner G, Adler LE, Freedman R (1984). Deficits in sensory gating in schizophrenic patients and their relatives. Evidence obtained with auditory evoked responses. Arch Gen Psychiatry 41: 607-612.

Siegel SJ, Connolly P, Liang Y, Lenox RH, Gur RE, Bilker WB et al (2003). Effects of strain, novelty, and NMDA blockade on auditory-evoked potentials in mice. Neuropsychopharmacology 28: $675-682$.

Sukov W, Barth DS (1998). Three-dimensional analysis of spontaneous and thalamically evoked gamma oscillations in auditory cortex. J Neurophysiol 79: 2875-2884.
Swerdlow NR, Geyer MA, Shoemaker JM, Light GA, Braff DL, Stevens KE et al (2006). Convergence and divergence in the neurochemical regulation of prepulse inhibition of startle and N40 suppression in rats. Neuropsychopharmacology 31: 506-515.

Turetsky BI, Calkins ME, Light GA, Olincy A, Radant AD, Swerdlow NR (2006). Neurophysiological endophenotypes of schizophrenia: the viability of selected candidate measures. Schizophr Bull 33: 69-94.

Umbricht D, Koller R, Bieber K (2004a). Ketamine-induced deficits in encoding in healthy volunteers: comparison to corresponding deficits in schizophrenia. Schizophr Res 67: 1.

Umbricht D, Vyssotky D, Latanov A, Nitsch R, Brambilla R, D'Adamo $\mathrm{P}$ et al (2004b). Midlatency auditory event-related potentials in mice: comparison to midlatency auditory ERPs in humans. Brain Res 1019: 189-200.

Umbricht D, Vyssotki D, Latanov A, Nitsch R, Lipp HP (2005). Deviance-related electrophysiological activity in mice: is there mismatch negativity in mice? Clin Neurophysiol 116: 353-363.

van Berckel BN, Oranje B, van Ree JM, Verbaten MN, Kahn RS (1998). The effects of low dose ketamine on sensory gating, neuroendocrine secretion and behavior in healthy human subjects. Psychopharmacology (Berl) 137: 271-281.

Ward PB, Hoffer LD, Liebert BJ, Catts SV, O’Donnell M, Adler LE (1996). Replication of a P50 auditory gating deficit in Australian patients with schizophrenia. Psychiatry Res 64: 121-135.

Zhang ZJ, Reynolds GP (2002). A selective decrease in the relative density of parvalbumin-immunoreactive neurons in the hippocampus in schizophrenia. Schizophr Res 55: 1-10.

Supplementary Information accompanies the paper on the Neuropsychopharmacology website (http://www.nature.com/ npp) 